\title{
STRESS AND COPING AMONG POLISH AND SLOVAK ATHLETES DURING THE SECOND STAGE OF THE COVID-19 PANDEMIC
}

\author{
Ryszard MAKAROWSKI ${ }^{*}$ \\ ${ }^{1}$ Elblag University of Humanities and Economics, Faculty of Health Sciences, Elblag, Poland \\ *Corresponding author: makarowski@wp.pl
}

https://doi.org/10.35189/dpeskj.2021.60.1.3

\begin{abstract}
The aim of this study was to estimate variability in experienced stress, the use of personal resources (resilience) in coping with stress and the Big Five personality traits among Polish and Slovak athletes. The study used the Perception of Stress Questionnaire to measure the following dimensions: emotional tension, external stress and intrapsychic stress. The Resilience Scale was also used, comprising five subscales: perseverance and determination, openness to new experiences and sense of humour, competences and tolerance of negative emotions, tolerance of failure and treating life as a challenge, optimism and the ability to mobilise in difficult situations. The IPIP-BFM was used to measure the following personality traits: extraversion, agreeableness, conscientiousness, emotional stability and intellect. Polish $(n=66)$ and Slovak $(n=99)$ athletes participated in the study during the so-called second stage of the COVID-19 pandemic, from January 1 to February 12, 2021. Results: a) stress levels among Polish and Slovak athletes depend on their personal resources, which include resilience and the Big Five personality traits, b) Slovak athletes are characterised by greater perseverance, openness to experience and sense of humour, tolerance of negative emotions, treating life as a challenge, optimism and the ability to mobilise in difficult situations, $c$ ) higher resilience among Slovak athletes is a probable cause of the lack of difference in stress levels among Polish and Slovak athletes, $d$ ) female athletes from Poland and Slovakia reported higher emotional tension, external stress and intrapsychic stress during the second stage of the pandemic than did male athletes.
\end{abstract}

Keywords: resilience, COVID-19 pandemic, athletes, Big Five, cross-cultural research.

\section{Introduction}

The severe acute respiratory syndrome coronavirus 2 (SARS-CoV-2) has spread at an unprecedented rate. Over 110,349,428 infections have been reported worldwide - on February 19, 2021 (Center for Systems Science and Engineering at Johns Hopkins University, 2020).

On February 11, 2021, the 14-day cumulative incidence rate per 100,000 people was 196,37 in Poland and 496,40 in Slovakia (Rządowe Centrum Bezpieczeństwa [Government Security Centre], 2021). These data show that the cumulative incidence rate per 1,000,000 people is almost three times higher in Slovakia than in Poland. In contrast to Poland where lockdown was lifted on January 1, 2021, it is currently still in effect in Slovakia. Going outside is limited, mass gatherings are prohibited, and businesses and services such as theatres, hairdressers' salons, drivers' education centres, swimming pools and gyms are closed. Churches and ski resorts are closed, and movement beyond the district level has been restricted. House visits between people who do not live together have also been banned. The state of emergency instituted on January 1, 2021, has been extended to March 20, 2021. On February 18, 2021 (the date of writing this article), Slovakia had the highest relative COVID-19 mortality rate in the world. Among all patients hospitalised due to COVID-19 in Slovak hospitals, 30\% die 
(Ministerstvo vnútra Slovenskej Republiky [Ministry of the Interior of the Slovak Republic], 2021).

Certain people are able to effectively cope with almost any crisis situation. Psychological resilience and coping with stress become especially important in the context of the current pandemic situation.

Italy was one of the most severely affected countries by the COVID-19 pandemic. One study of 1,132 athletes compared their stress levels before the pandemic and during its initial stage (Fronso et al., 2020). It showed that women reported higher stress than men, while elite athletes reported lower stress than beginners.

The International Federation of Professional Footballers' Associations and national football associations carried out a study on 1,602 professional football players from those countries that have implemented far-reaching measures to combat the spread of the pandemic. Twenty two percent of female and $13 \%$ of male football players reported depression symptoms, while $18 \%$ and $16 \%$, respectively, reported anxiety disorder symptoms (FIFPRO, 2020). A study carried out between March 23 and April 14, 2020, showed that the proportion of professional football players reporting depression symptoms doubled (Schinke et al., 2020). The fact that many athletes training in various sports (athletics, hockey, karate, cricket, rugby, basketball, etc.) reported depression was confirmed by Pillaya et al. (2020). They also highlighted that a significant number of athletes experienced changes in their sleep cycles, switched to a more sedentary rather than active lifestyle and consumed excessive amounts of carbohydrates. Most athletes had access to healthcare during the pandemic (the lockdown period) and required appropriate motivation for physical activity. Finally, the impact of the pandemic on student athletes has to be mentioned - over 37,000 students responded to a questionnaire published by the NCAA Science Institute in the period between April 10 and May 1, 2020. The results showed that the majority of student athletes experienced mental disorders, and over one-fourth reported feeling very lonely, sad, mentally exhausted and having experienced a sense of loss (Metrifit, 2020).

The lockdown was revealed to be an effective public health solution preventing the spread of COVID-19. Droit-Volet et al. (2020) examined the impact of experienced stress due to COVID-19 on the individual experience of time. The study included 4,364 French men and women. The results showed that the participants experienced a slower passage of time during the lockdown. Significant increases in boredom and sadness were reported. The literature on boredom suggests that it is related to various behaviours and psychological factors. Boredom is associated with problems such as substance abuse, depression, anxiety and compulsive eating (Danckert \& Allman 2005; Vodanovich, 2003). Boredom is considered to be an important signal of the need to change one's behaviour by seeking more satisfying situations (Wolff et al., 2020). Some authors argue for the beneficial effects of boredom. However, this leads to the question of individual abilities to cope with boredom in industrial societies. Differences in these abilities might be a predictor of psychological difficulties and health problems, including depression (Hamilton et al., 1984). Thus, this is a significant problem in the lockdown context.

In Spain, the lockdown lasted for 100 days and necessitated a sudden suspension of sports training and competitions. The study by Pons et al. (2020), which included 544 young athletes, collected information about living conditions and training; it also used the Holistic Monitoring Questionnaire (HMQ) and the General Health Questionnaire-12 (GHQ-12). The results showed 
a general negative impact of the pandemic on the lives and mental health of young athletes, though the participants could be divided into three clusters. The first cluster, comprising $54.78 \%$ of the sample, experienced a small negative impact due to the lockdown. The second cluster (29.96\% of the sample) reported an average negative impact, while the third cluster (15.26\% of the sample) reported a severe negative impact.

\section{Hypotheses}

Based on a literature review as well as the fact that Slovakia has implemented significantly greater restrictions that Poland, the following hypotheses were put forward in the current study:

H1: Stress levels will be higher among Slovak than Polish athletes.

H2: Resilience levels (perseverance and determination, openness to new experiences and sense of humour, competences and tolerance of negative emotions, tolerance of failure and treating life as a challenge, respectively optimism and the ability to mobilise in difficult situations) will be higher among Polish than Slovak athletes.

H3: Higher levels of personality traits (extraversion, agreeableness, conscientiousness, emotional stability and intellect) will be observed in Polish rather than Slovak athletes.

\section{Methodology}

\section{Participants}

One hundred and fifty athletes (85 women and 65 men) who trained in various individual and team sports as part of a sports club for a period of at least one year took part in the study. They were athletes from Poland $(n=61)$ and Slovakia. The study was carried out in January and February 2021.

\section{Instruments}

\section{Stress levels}

The Perception of Stress Questionnaire - KPS (Plopa \& Makarowski, 2010) was used to measure the intensity of subjectively perceived stress. The questionnaire consists of 27 items forming four subscales: emotional tension (seven items, e.g., "I get nervous more often than I used to, and for no obvious reason"), external stress (seven items, e.g., "I am criticised too frequently") and intrapsychic stress (seven items, e.g., "Thinking about my problems makes it hard for me to fall asleep"), as well as the lying subscale (six items, e.g., "I have sometimes not kept my word"). The respondents indicate their agreement with each item on a five-point Likert-type scale (1 - Untrue, 5 - True). The higher the total score or the partial score on each of the subscales, the greater the subjective perception of stress.

\section{Resilience}

To measure resilience, the Resilience Scale (Skala Pomiaru Prężności) by Ogińska-Bulik and Juczyński (2008) was used. The scale consists of 25 items arranged into five subscales (five items for each subscale): perseverance and determination (e.g., "I try to overcome challenges regardless of how difficult they are), openness to new experiences and sense of 
humour (e.g., "I can see the funny side of the situations I have to face"), personal coping competences and tolerance of negative emotions (e.g., "I can adjust to all situations, even the most difficult ones), tolerating failures and treating life as a challenge (e.g., "I easily adapt to new situations"), and optimistic attitude to life and the ability to mobilise in difficult situations (e.g., "I notice many solutions in difficult situations"). The respondents indicate their agreement with each item on a five-point Likert-type scale (0 - Definitely disagree, 4 Definitely agree). The higher the partial scores on each scale or the total score, the higher the degree of resilience.

\section{The IPIP-BFM-20 Questionnaire}

The IPIP-BFM (16/20/50) personality questionnaire by Goldberg $(1990,1992)$, in the Polish adaptation by Struś et al. (2014), reflects the lexical model of personality. The IPIP consists of 20 items with responses given on a five-point Likert-type scale (1 - Does not describe me at all; 5 - Describes me very well). The IPIP scores comprise five subscales: 1) Extraversion; 2) Agreeableness; 3) Conscientiousness; 4) Emotional stability; 5) Intellect. The characteristics of extraversion, conscientiousness and agreeableness - components of the so-called Big Five are widely known. The authors of the IPIP characterise people with high levels of emotional stability as: calm, measured, not easily susceptible to negative emotional states. On the other hand, people with low emotional stability are: anxious, nervous, prone to changes in mood and to worrying, oversensitive, as well as jealous, irritable and quick to anger. Those scoring high in intellect can be characterised as: intellectually active and cognitively open, creative, reflexive, imaginative and having many interests. Low intellect is related to lack of imagination, creativity and reflection, as well as literal-mindedness.

\section{Results}

The age and gender proportions of the samples were relatively similar (Table 1).

Table 1. Descriptive statistics of the sample

\begin{tabular}{lccccc}
\hline \multicolumn{1}{c}{ Country } & $N$ & Women & Men & $M_{\text {age }}$ & $S D$ \\
\hline Poland & 61 & 34 & 27 & 24.45 & 6.11 \\
Slovakia & 89 & 51 & 38 & 23.32 & 5.38 \\
Sum & 150 & 85 & 65 & & \\
\hline
\end{tabular}

The results were compared between the groups. It was assumed that the groups would differ on the measured variables. To test these differences, Student's $t$ test was used, as the variables assumed a normal distribution (kurtosis and skewness were below 1). 
Table 2. Differences in stress, resilience and Big Five trait levels between Polish and Slovak athletes

\begin{tabular}{|c|c|c|c|c|c|c|c|}
\hline \multirow[b]{2}{*}{ Variables } & \multicolumn{2}{|c|}{ Poland } & \multicolumn{2}{|c|}{ Slovakia } & \multirow[b]{2}{*}{$\mathrm{t}$} & \multirow[b]{2}{*}{ two-way $p$} & \multirow[b]{2}{*}{ Cohen's d } \\
\hline & M & SD & M & $\mathrm{SD}$ & & & \\
\hline Emotional tension & 15.33 & 6.03 & 16.42 & 6.00 & -1.120 & ns. & 0.18 \\
\hline External stress & 17.16 & 5.71 & 18.47 & 5.65 & -1.419 & ns. & 0.23 \\
\hline Intrapsychic stress & 13.02 & 5.06 & 14.45 & 4.92 & -1.778 & ns. & 0.29 \\
\hline Total KPS score & 45.51 & 15.54 & 49.35 & 14.88 & -1.561 & ns. & 0.25 \\
\hline Perseverance and determination & 14.93 & 2.73 & 16.49 & 3.22 & -3.149 & $* *$ & 0.52 \\
\hline $\begin{array}{l}\text { Openness to new experiences } \\
\text { and sense of humour }\end{array}$ & 16.03 & 3.04 & 18.80 & 2.11 & -6.773 & $* * *$ & 1.06 \\
\hline $\begin{array}{l}\text { Competences and tolerance of } \\
\text { negative emotions }\end{array}$ & 14.97 & 2.96 & 17.08 & 2.92 & -4.430 & $* * *$ & 0.72 \\
\hline $\begin{array}{l}\text { Tolerance of failure and treating } \\
\text { life as a challenge }\end{array}$ & 15.39 & 2.72 & 17.08 & 2.93 & -3.634 & $* * *$ & 0.60 \\
\hline $\begin{array}{l}\text { Optimism and the ability to } \\
\text { mobilise in difficult situations }\end{array}$ & 13.67 & 3.66 & 15.68 & 3.23 & -3.620 & $* * *$ & 0.58 \\
\hline Total resilience score & 75.00 & 13.16 & 85.13 & 11.03 & -5.238 & $* * *$ & 0.83 \\
\hline Extraversion & 12.57 & 1.64 & 13.54 & 1.78 & -3.420 & ** & 0.56 \\
\hline Agreeableness & 11.84 & 1.60 & 12.83 & 1.92 & -3.372 & ** & 0.56 \\
\hline Conscientiousness & 11.31 & 2.02 & 11.91 & 1.87 & -1.904 & ns. & 0.31 \\
\hline Emotional stability & 12.11 & 1.64 & 12.71 & 1.80 & -2.086 & $*$ & 0.34 \\
\hline Intellect & 11.59 & 1.62 & 12.30 & 1.47 & -2.863 & $*$ & 0.46 \\
\hline
\end{tabular}

The results in Table 2 show that the groups did not differ to a statistically significant degree in terms of stress levels. Statistically significant differences occurred on all dimensions of resilience. Slovak athletes achieved higher scores on all dimensions. The analyses also show that the groups differed on the Big Five personality traits (except conscientiousness). Here, the Slovak group reported higher scores as well.

The stress levels between women and men were compared in the Slovak and Polish groups.

Table 3. Stress level differences between female and male athletes in the Slovak and Polish groups

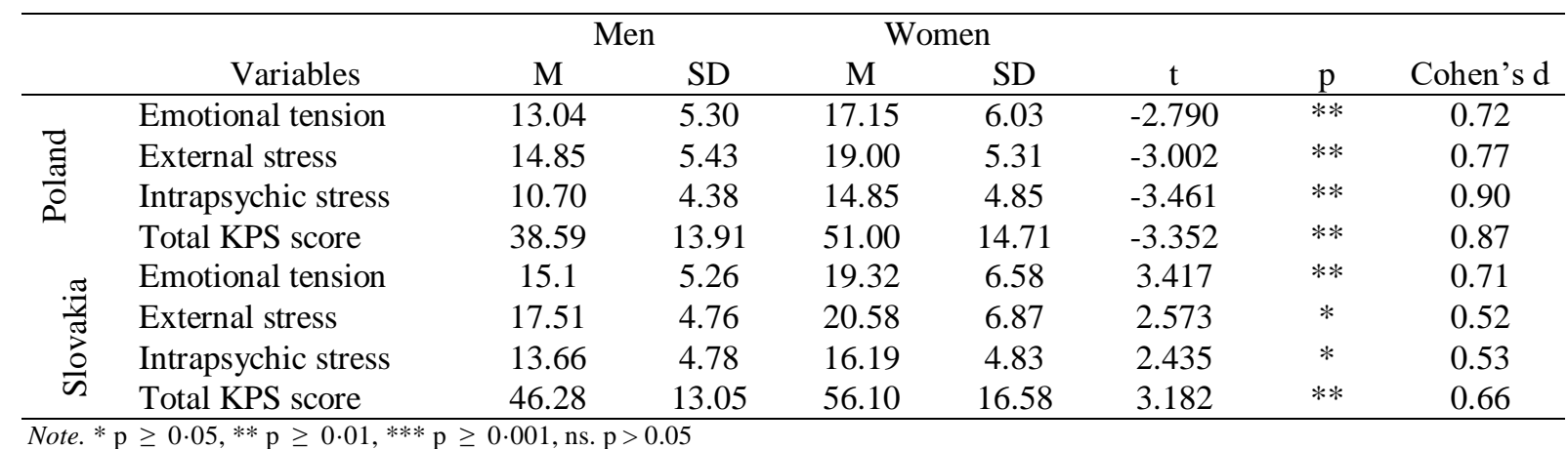

The results in Table 3 show that statistically significant differences between women and men occurred in both groups. In both groups, women reported higher stress levels. 


\section{Discussion}

The first hypothesis, stating that stress levels would be higher among Slovak than Polish athletes, was not confirmed. This is a surprising result. Here, it is worth mentioning the author's study on athletes from Poland and Slovakia (among others) carried out during the first stage of the pandemic, that is, between March and July 2020 (Makarowski et al., 2020). It showed no statistically significant differences in experienced stress between Polish and Slovak athletes. The results suggested that the direct consequences of the pandemic were not related to an increase in subjectively experienced psychological stress among athletes from countries variously affected by the pandemic (including Romania). During the pandemic, most athletes were characterised by low levels of stress: emotional tension, external stress and intrapsychic stress. Based on the study by Tan et al. (2020), it can be predicted that athletes will be at a low risk for COVID-19 infection.

In the current study concerning the second stage of the pandemic (January - February 2021), we mention that $10 \%$ of the Polish athletes were infected with COVID-19, compared to $7 \%$ of the Slovak athletes.

The study by Castro-Sánchez et al. (2018) shows that athletes who have direct contact with other athletes experience lower stress compared to those who do not. Considering that Slovak athletes are currently unable to be in direct contact with anyone but their close families, while Polish athletes have no such restrictions and can train together, the latter should have reported lower stress. However, data in Table 2 show that no statistically significant differences in stress levels, emotional tension, external stress and intrapsychic stress occurred between Polish and Slovak athletes. These results are similar to the results of the studies carried out during the first stage of the pandemic, as mentioned above (Makarowski et al., 2020).

Why did Slovak athletes report similar stress levels to Polish athletes despite being placed under especially severe restrictions due to the state of emergency in Slovakia? Analysing the data in Table 2 gives a partial answer to this question by showing that Slovak athletes achieved higher scores on each of the resilience dimensions. This means that their personal resources are higher than those of Polish athletes (Hobfoll, 2006). They are more optimistic, perseverant, tolerant of failure and they treat life as a challenge. Perhaps the ability to approach life like a sports competition facilitates more effective coping with stress.

Various studies (Asendorpf et al., 2001; Robins et al., 1996; Schnabel et al., 2002) present a relatively stable description of personality types: the resilient type (low neuroticism, high conscientiousness, high extraversion, average agreeableness and openness), the overcontrolled type (high neuroticism and low extraversion, with average levels of the remaining traits), as well as the undercontrolled type (low conscientiousness and below-average agreeableness, with average or above-average levels of the remaining traits). In the normal population, these types can be characterised as follows:

- the undercontrolled type - extraverted tendencies, high level of antisocial behaviours, difficulties in relationships, impulsivity;

- the resilient type - optimal social adaptation and emotional stability;

- the overcontrolled type - introverted tendencies, shyness, withdrawal, low self-esteem in social situations, loneliness. 
An international study on representative samples of women and men from Spain $(n=420)$, Italy $(n=322)$, the US $(n=499)$ and Poland $(n=235)$ confirmed the ability to distinguish these three personality types in many societies, regardless of gender and cultural differences (Asendorpf et al., 2001). Both the undercontrolled and the overcontrolled types exhibit lower social adaptation compared to the resilient type, although they constitute a relatively large part of the normal population ( $25 \%$ each). The resilient type is represented by about $50 \%$ of the population and it comprises people exhibiting optimal social adaptation (Block \& Block, 1980). Thus, it can be said that the resilient personality type will be related to better functioning in a crisis situation such as the ongoing COVID-19 pandemic.

The results in Table 2 show that higher extraversion, agreeableness, emotional stability and intellect were observed among Slovak athletes. It can be assumed that Slovak athletes are more resilient than Polish athletes. This might be the chief reason why the second and third hypotheses were not confirmed.

However, it must be added that explaining the phenomenon of the Slovak athletes' relatively high functioning might also be related to other factors such as the intensity and development of the pandemic, the influence of the media, unemployment levels, the current economic and political situation in a given country, the quality of healthcare and personal experiences with people who have been infected with the SARS-CoV-2.

Because the pandemic might have long-term consequences, it is important to monitor the athletes' mental state also after the pandemic. The current study can be of use not only to professional athletes but also to coaches and sports psychologists promoting the most effective strategies of coping with stress.

In an attempt to explain why women reported higher stress levels than men in the current study, the Italian study by Fronso et al. (2020) bears mention. They measured 1,113 athletes during the pandemic. Statistically significant differences between genders in terms of perceived stress have been well-established in the literature (Day \& Livingstone, 2003; Brebner, 2003). These results can be interpreted by reference to the so-called response styles theory (NolenHoeksema, 1990). It posits that women have a tendency towards rumination when they experience negative moods or circumstances, while men have a tendency towards distraction. Rumination causes anxiety and negative emotions. In turn, this can increase emotional tension, which is one of the elements of stress (Hankin \& Abramson, 1999). On the other hand, male athletes usually report greater economic stability than female athletes. Lack of economic stability due to the pandemic can cause female athletes to suffer from depression more often than male athletes (Hankin \& Abramson, 1999). However, to better explain this difference, other factors should also be considered, such as differences in emotion regulation and coping strategies especially in periods where training and competing are not possible, reductions in income, infection risk, or risk of career cessation (de Arrieta \& Arenaza, 2019; Predoiu et al., 2020).

\section{Conclusion}

All three hypotheses were not confirmed. The following conclusions can be drawn:

- The cumulative incidence rate of SARS-CoV-2 per 100,000 people is almost three times higher in Slovakia than in Poland. In mid-February 2021, the relative COVID-19 
mortality rate in Slovakia was the highest in the world. From January 1 until March 20, 2021, Slovakia was placed in a state of emergency, which drastically reduced freedom of movement.

- Stress levels among Polish and Slovak athletes depend on their personal resources, which include resilience and the Big Five personality traits.

- Slovak athletes are characterised by greater perseverance, openness to experience and sense of humour, tolerance of negative emotions, treating life as a challenge, optimism and the ability to mobilise in difficult situations.

- Higher resilience among Slovak athletes is a probable cause of the lack of difference in stress levels among Polish and Slovak athletes.

- Female athletes from Poland and Slovakia reported higher emotional tension, external stress and intrapsychic stress during the second stage of the pandemic than did male athletes.

\section{References}

Asendorpf, J. B., Borkenau, P., Ostendorf, F., \& Van Aken, M. G. (2001). Carving personality description at its joints: Confirmation of three replicable personality prototypes for both children and adults. European Journal of Personality, 15(3), 169-198. https://doi.org/10.1002/per.408

Brebner, J. (2003). Gender and emotions. Personality and Individual Differences, 34(3), 387394. https://doi.org/10.1016/S0191-8869(02)00059-4

Castro-Sánchez, M., Zurita-Ortega, F., Chacón-Cuberos, R., López-Gutiérrez, C. J., \& ZafraSantos, E. (2018). Emotional intelligence, motivational climate and levels of anxiety in athletes from different categories of sports: Analysis through structural equations. International Journal of Environmental Research and Public Health, 15(5): 894. https://doi.org/10.3390/ijerph15050894

Center for Systems Science and Engineering at Johns Hopkins University. (2020). COVID-19 dashboard.

https://gisanddata.maps.arcgis.com/apps/opsdashboard/index.html\#/bda7594740fd402994 23467b48e9ecf6

Danckert, J. A., \& Allman, A.-A. A. (2005). Time flies when you're having fun: Temporal estimation and the experience of boredom. Brain and Cognition, 59(3), 336-345. https://doi.org/10.1016/j.bandc.2005.07.002

Day, A. L., \& Livingstone, H. A. (2003). Gender differences in perceptions of stressors and utilization of social support among university students. Canadian Journal of Behavioural Science, 35(2), 73-83. https://doi.org/10.1037/h0087190

de Arrieta, P., \& Arenaza, J. G. (2019). Affective disorders and gender differences. In M.-S. Herrero (Ed.), Psychopathology in women: Incorporating gender perspective into descriptive psychopathology (pp. 611-638). Springer.

Droit-Volet, S., Gil, S., Martinelli, N., Andant, N., Clinchamps, M., Parreira, L., Rouffia, C. K., Dambrun, M., Huguet, P., Dubuis, B., Pereira, B., Bouillon, J-B., \& Dutheil, F. (2020). Time and Covid-19 stress in the lockdown situation: Time free, "dying" of boredom and sadness. PLoS ONE, 15(8), 1-15. https://doi.org/10.1371/journal.pone.0236465

FIFPRO. (2020). Players in lockdown: How to keep your mind sharp. https://www.fifpro.org/en/health/coronavirus-shutdown-sharp-rise-in-players-reportingdepression-symptoms 
Fronso, S., Costa, S., Montesano, C., Di Gruttola, F., Ciofi Edoardo, G., Morgilli, L., Robazza, C., \& Bertollo, M. (2020). The effects of COVID-19 pandemic on perceived stress and psychobiosocial states in Italian athletes. International Journal of Sport and Exercise Psychology, 1-13. https://doi.org/10.1080/1612197X.2020.1802612

Goldberg, L. R. (1990). An alternative "description of personality": The Big Five factor structure. Journal of Personality and Social Psychology, 59(6), 1216-1229. https://doi.org/10.1037//0022-3514.59.6.1216

Goldberg, L. R. (1992). The development of markers of Big Five factor structure. Psychological Assessment, 4(1), 26-42. https://doi.org/10.1037/1040-3590.4.1.26

Hamilton, J. A., Haier, R. J., \& Buchsbaum, M. (1984). Intrinsic enjoyment and boredom coping scale: Validation with personality, evoked potential and attention measures. Personality and Individual Differences, 5(2), 183-193. https://doi.org/10.1016/0191-8869(84)90050-3

Hankin, B. L., \& Abramson, L. Y. (1999). Development of gender differences in depression: Description and possible explanations. Annals of Medicine, 31(6), 372-379. https://doi.org/10.3109/07853899908998794

Hobfoll, S. E. (2006). Stres, kultura i społeczność. Psychologia i filozofia stresu [Stress, culture and community. Psychology and philosophy of stress]. Gdańskie Wydawnictwo Psychologiczne.

Makarowski, R., Piotrowski, A., Predoiu, R., Görner, K., Predoiu, A., Mitrache, G., Malinauskas, R., Bochaver, K., Dovzhik, L., Cherepov, E., Vazne, Z., Vicente-Salar, N., Hamzah, I., Miklós, M., Kovács, K., \& Nikkhah-Farkhani, Z. (2020). Stress and coping during the COVID-19 pandemic among martial arts athletes - A cross-cultural study. Archives of Budo, 16, 161-171. WOS: 000579417600001

Metrifit. (2020). Dealing with athlete stress and anxiety. https://metrifit.com/blog/why-athletes-should-monitor-stress/

Ministerstvo vnútra Slovenskej Republiky. (2021). COVID-19. https://www.minv.sk/

Nolen-Hoeksema, S. (1990). Sex differences in depression. Stanford University Press.

Ogińska-Bulik N., \& Juczyński Z. (2008). Skala Pomiaru Prężności (SPP-25) [Resilience Measurement Scale - SPP-25]. Nowiny Psychologiczne, 3, 39-56.

Predoiu, R., Makarowski, R., Görner, K., Bota, A., Predoiu, A., Mitrache, G., \& Grigore, V. (2020). Key personality traits of martial arts and world's top coaches - Impact on future martial arts specialists. Archives of Budo, 16, 129-142. WOS: 000579413000001

Pillaya, L., Janse van Rensburga, D. C., Jansen van Rensburga, A., Ramagolea, D., Holtzhausena, L., Dijkstrac, P., \& Cronjee, T. (2020). Nowhere to hide: The significant impact of coronavirus disease 2019 (COVID-19) measures on elite and semi-elite South African athletes. Journal of Science and Medicine in Sport, 23(7), 670-679. https://doi.org/10.1016/j.jsams.2020.05.016

Plopa, M., \& Makarowski, R. (2010). Kwestionariusz Poczucia Stresu. Podręcznik [The Perception of Stress Questionnaire. Coursebook]. Vizja Press \& IT.

Pons, J., Ramis, Y., Alcaraz, S., Jordana, A., Borrueco, M., \& Torregrossa, M. (2020). Where did all the sport go? Negative impact of COVID-19 lockdown on life-spheres and mental health of Spanish young athletes. Frontiers in Psychology, 11, 611-872. https://doi.org/10.3389/fpsyg.2020.611872

Robins, R. W., John, O. P., Caspi, A., Moffitt, T. E., \& Stouthamer-Loeber, M. (1996). Resilient, overcontrolled, and undercontrolled boys: Three replicable personality types. Journal of Personality and Social Psychology, 70(1), 157-171. https://doi.org/10.1037/0022-3514.70.1.157

Rządowe Centrum Bezpieczeństwa. (2021). Raport dobowy COVID-19 [COVID-19 daily report]. https://rcb.gov.pl/raport-dobowy-covid-19/ 
Schinke, R., Papaioannou, A., Maher, Ch. Parham, W. D., Larsen, C. H., Gordin, R., \& Cotterill, S. (2020). Sport psychology services to professional athletes: Working through COVID-19. International Journal of Sport and Exercise Psychology, 18(4), 409-413. https://doi.org/10.1080/1612197X.2020.1766182

Schnabel, K., Asendorpf, J. B., \& Ostendorf, F. (2002). Replicable types and subtypes of personality: German NEO-PI-R versus NEO-FFI. European Journal of Personality, 16(1), 7-24. https://doi.org/10.1002/per.445

Struś, W., Cieciuch, J., \& Rowiński, T. (2014). Polish adaptation of the IP1P-BFM-50 questionnaire to measure five personality traits in the lexical approach. Annals of Psychology, 17(2), 327-346.

Tan, T., Khoo, B., Mills, E., Phylactou, M., Patel, B., Eng, P., Thurston, L., Muzi, B., Meeran, K., Prevost, A., Comninos, A., Abbara, A., \& Dhillo, W. (2020). Association between high serum total cortisol concentrations and mortality from COVID-19. The Lancet Diabetes \& Endocrinology, 8(8), 659-660. https://doi.org/10.1016/s2213-8587(20)30216-3

Vodanovich, S. (2003). Psychometric measures of boredom: A review of the literature. The Journal of Psychology, 137(6), 569-595. https://doi.org/10.1080/00223980309600636

Wolff, W., Martarelli, C., Schuler, J., \& Bieleke, M. (2020). High boredom proneness and low trait self-control impair adherence to social distancing guidelines during the COVID-19 pandemic. International Journal of Environmental Research and Public Health, 17(15): 5420. https://doi.org/10.3390/ijerph17155420 